\title{
Glycopolymer Grafted Silica Gel as Chromatographic Packing Materials
}

\author{
Gaoqi Ma ${ }^{1,2}$, Xitao Luo ${ }^{2,3}$, Xitong Sun ${ }^{2}$, Weiyan Wang ${ }^{1, *}$, Qinghui Shou ${ }^{2, *}$, Xiangfeng Liang ${ }^{2, *}$ \\ and Huizhou Liu ${ }^{2}$ \\ 1 School of Chemical Engineering, Xiangtan University, Xiangtan 411105, China; Magq@smail.xtu.edu.cn \\ 2 CAS Key Laboratory of Bio-Based Materials, Qingdao Institute of Bioenergy and Bioprocess \\ Technology (QIBEBT), Chinese Academy of Sciences (CAS), Qingdao 266101, China; \\ luoxt@qibebt.ac.cn (X.L.); sunxt@dicp.ac.cn (X.S.); hzliu@ipe.ac.cn (H.L.) \\ 3 University of Chinese Academy of Sciences, Shijingshan District, Beijing 100049, China \\ * Correspondence: wangweiyan@xtu.edu.cn (W.W.); shouqh@qibebt.ac.cn (Q.S.); liangxf@qibebt.ac.cn (X.L.); \\ Tel.: +86-532-5856-8201 (Q.S.)
}

Received: 31 October 2018; Accepted: 18 December 2018; Published: 20 December 2018

\begin{abstract}
The modification of the surface of silica gel to prepare hydrophilic chromatographic fillers has recently become a research interest. Most researchers have grafted natural sugar-containing polymers onto chromatographic surfaces. The disadvantage of this approach is that the packing structure is singular and the application scope is limited. In this paper, we explore the innovative technique of grafting a sugar-containing polymer, 2-gluconamidoethyl methacrylamide (GAEMA), onto the surface of silica gel by atom transfer radical polymerization (ATRP). The $\mathrm{SiO}_{2}$-g-GAEMA with ATRP reaction time was characterized by Fourier infrared analysis, Thermogravimetric analysis (TGA), and elemental analysis. As the reaction time lengthened, the amount of GAEMA grafted on the surface of the silica gel gradually increased. The GAEMA is rich in amide bonds and hydroxyl groups and is a typical hydrophilic chromatography filler. Finally, $\mathrm{SiO}_{2}$-g-GAEMA (reaction time $=24 \mathrm{~h}$ ) was chosen as the stationary phase of the chromatographic packing and evaluated with four polar compounds (uracil, cytosine, guanosine, and cytidine). Compared with unmodified silica gel, modified silica gel produces sharper peaks and better separation efficiency. This novel packing material may have a potential for application with highly isomerized sugar mixtures.
\end{abstract}

Keywords: glycopolymers; ATRP; $\mathrm{SiO}_{2}$-g-GAEMA; packing materials

\section{Introduction}

The synthesis of sugar-based monomers and polymers has been widely reported over the last two decades. The carbohydrate residues confer high hydrophilicity and water solubility and they are widely applied in macromolecular drugs [1], drug delivery [2], cell targeting, and adhesion [3,4]. Use of such polymers as stationary in separation applications and bioassays has also been suggested for structure-controllable sugar polymers [5]. Glycopolymers, defined as functional polymer materials comprising sugar moieties as pendant or terminal groups, have attracted great attention as model systems to study the specific molecular recognition functions of saccharides [6]. The side glycosyl groups are composed by one, two or more saccharides including monosaccharide, disaccharide, or oligosaccharide, or they comprise a synthetic polymer. Compared with natural sugar complexes, glycopolymers have a well-defined structure and composition, and they can be chemically designed and synthesized based on the actual scientific issues, such as hydrogels [7], degradable materials [8], biomedical materials [9].

A wide range of applications of glycopolymers with the feature of pendent carbohydrate moieties exist, so it is necessary to control the structure with respect to attributes such as glycosylation 
density, position, and molecular weight. Controlling the molecular chain length of sugar-containing polymers is also necessary to achieve the polymer's desired properties in a particular application [10]. Except for the large distribution of the hydroxyl group, the fraction of amide is the only highly distributed moiety in the polymer grafted onto the surface of silica particles. Both hydroxyl and amide bonds are functional groups with a strong polarity. The sugar-containing polymers possessing the above characteristics have potential applications for hydrophilic interaction liquid chromatography (HILC). HILC, one chromatographic mode with good separation ability of strongly polar compounds, was first proposed in 1990 [11]. The binding of monosaccharides [12], maltose, isosorbide [13], and oligosaccharides [14] on the surface of silica gel has also been reported. However, these natural sugar structures are only suitable for analysis in specific fields. It is also meaningful to develop a synthetic sugar-containing polymer. In chromatography, extreme differences in polarity could be produced, which is critical to the separation of agents with a similar structure. In this work, glycopolymers were grafted onto the surface of the silica gel for further use as packing materials.

Generally, three methods are available to covalently graft polymer chains onto a silica surface: (1) The "grafting to" technique, where polymers are first synthesized and then introduced onto the surface through binding between the polymers' reactive end group and the surface functional group of the silica; (2) the "grafting through" method, where a macromonomer with a functional terminal group is synthesized, and the end groups are polymerized to form the main chain; (3) and the "grafting from" approach, where the polymer chain grows from an initiator-functionalized self-assembled monolayer or initiator-modified particle surface [15]. A mechanism diagram of the three grafting modes is shown in Figure 1. Preparation of polymers with a high grafting density by using grafting to techniques is quite difficult because of the steric hindrance imposed by dense grafting. Although by using grafting through methods one can obtain a covalently bound side chain on each repeating unit of the backbone, the concentration of the polymerization end group is necessarily low, and the steric hindrance at the end of the propagation chain is large, resulting in a slow polymerization process and relatively low conversion rates [16]. Instead, using grafting from approaches can involve growth of polymer chains from solid surfaces by means of surface-initiated polymerization (SIP) of monomers. However, limitations arise from a synthetic perspective of this method (e.g., high polymer dispersity index-PDI) [17].

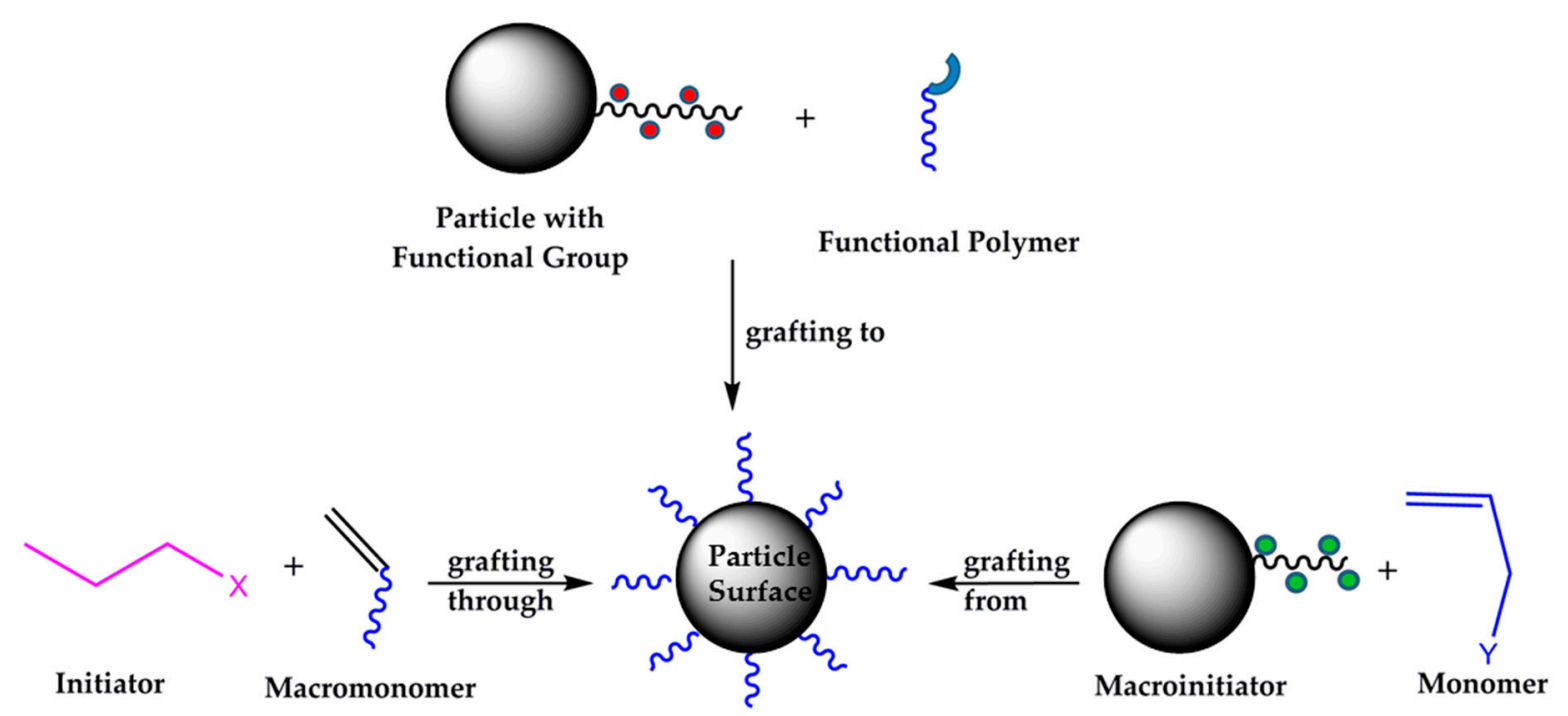

Figure 1. Three main strategies for grafting polymers on solid surfaces: Grafting to, grafting through, and grafting from. The terminal double bond, one typical polymerization unit, is drawn.

In the methods described above, shortage in polymer structure, dispersion, and terminal functional groups can be compensated for by the atom transfer radical polymerization (ATRP) 
methods pioneered by Matyjaszewski [18]. Among the controlled polymerization techniques, ATRP has attracted a great deal of attention in the past few years. Generally, the reaction proceeds with organic halogens as the initiator and transition metal salts such as $\mathrm{CuBr} / \mathrm{PMDETA}$ as the catalyst (see Scheme 1). During the polymerization process, the halogen atom is reversibly transferred and related to the dormant polymer chain. The addition of the transition metal and the ligand (L) catalyst can cause the dormant species to lose the halogen atom and generate an alkoxy radical active chain and oxidation state catalyst, which form a propagating radical and deactivator complex by a reversible halogen-atom transfer reaction. During the reaction, by controlling the concentration of the free radical active species, the side reaction caused by the irreversible bimolecular termination can be reduced, to better control the polymerization reaction.

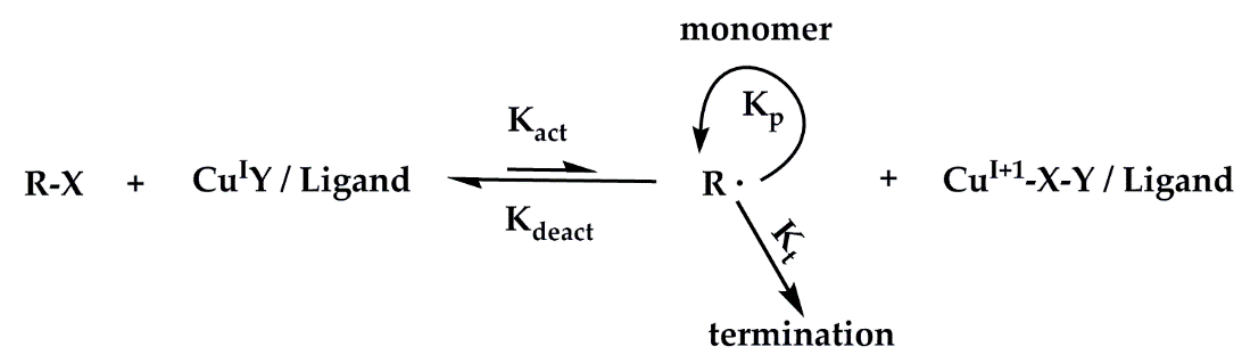

Scheme 1. Reaction mechanism of atom transfer radical polymerization (ATRP).

Taking these factors into consideration, we constructed a glycopolymer (2-gluconamidoethyl methacrylamide-GAEMA) [19] grafted onto a silica surface. This was used as a packing material for high performance liquid chromatography (HPLC) in separating model materials, including uracil, adenosine, cytosine, and cytidine. GAEMA contains a high density of amide and hydroxyl groups, making it attractive as a polar stationary phase because of its high hydrophilicity of these groups. Because of the dual binding between the amide and hydroxyl groups with the polar solutes in the mobile phase, the two structurally similar isomers may be effectively separated.

\section{Results and Discussion}

\section{1. $\mathrm{SiO}_{2}$-g-poly (2-gluconamidoethyl methacrylamide)}

The GAEMA monomer was synthesized without using any protecting group by Narain et al. [5,20]. For the first time, we reported the grafting of the sugar-containing monomer GAEMA onto the surface of silica gel by ATRP. During the polymerization, $\mathrm{Cu}^{2+}$ was introduced by adding a small amount of copper chloride to act as a deactivator, reducing the reaction rate and making the reaction controllable [21]. The glycomonomers were characterized by ${ }^{1} \mathrm{H}$ and ${ }^{13} \mathrm{C}$ nuclear magnetic resonance (NMR) spectra. The structural characterization of Scheme 2 (5) was carried out by spectroscopic (Fourier Transform infrared spectroscopy—FTIR), and thermoanalytical methods (thermogravimetric analysis-TGA). The surface grafting ratio of the silica gel was calculated by elemental analysis. 
( I )

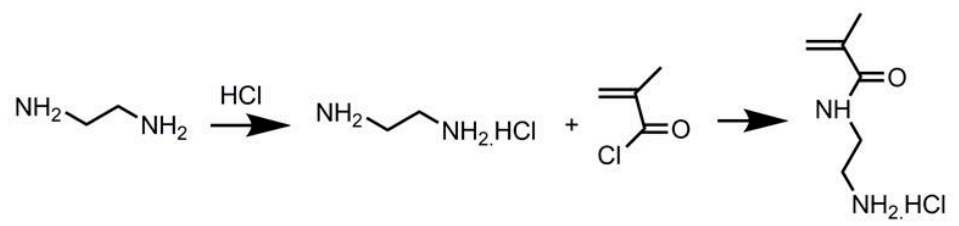

(1)

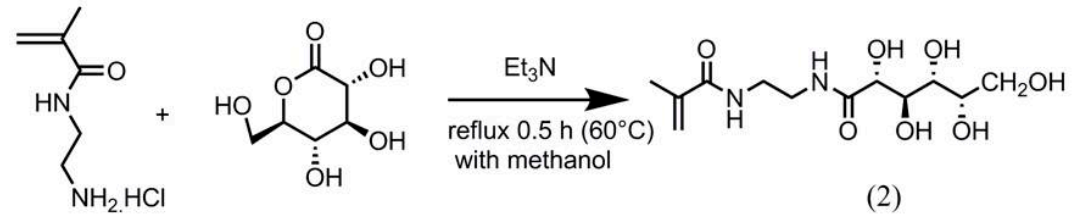

(III)
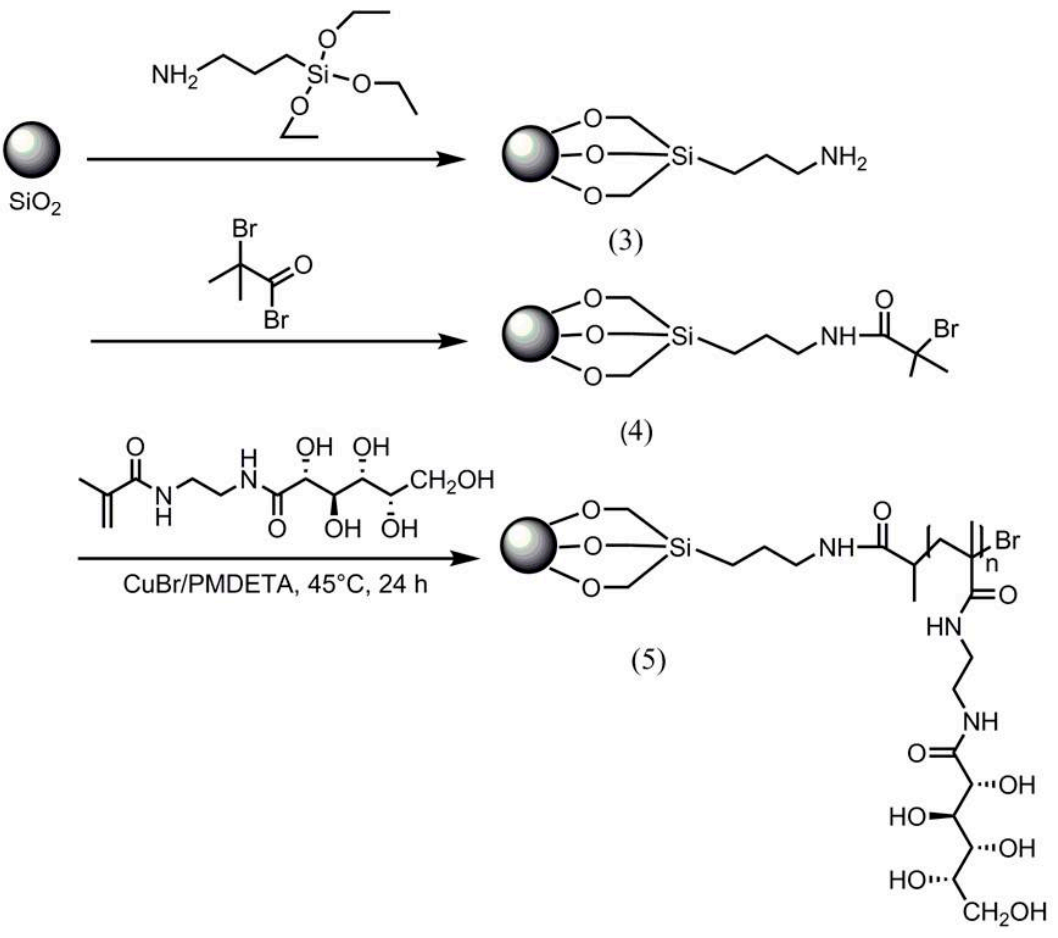

Scheme 2. Synthesis steps for the preparation of $\mathrm{SiO}_{2}$-g-GAEMA.

\subsection{IR Analysis}

Figure 2 shows the FT-IR spectra of (a) bare $\mathrm{SiO}_{2}$, (b) $\mathrm{SiO}_{2}-\mathrm{NH}_{2}$, (c) $\mathrm{SiO}_{2}-\mathrm{Br}$, (d) $\mathrm{SiO}_{2}$-g-GAEMA (reaction time $=6 \mathrm{~h}$ ), (e) $\mathrm{SiO}_{2}$-g-GAEMA (reaction time $=12 \mathrm{~h}$ ), and (f) $\mathrm{SiO}_{2}$-g-GAEMA (reaction time $=24 \mathrm{~h}$ ). For bare $\mathrm{SiO}_{2}$ particles, $1089.08 \mathrm{~cm}^{-1}$ belonged to the stretching vibration peak of $\mathrm{Si}-\mathrm{O}-\mathrm{Si} ; 3302.00 \mathrm{~cm}^{-1}$ was attributed to the free hydroxyl vibration peak (which is associated with $\mathrm{O}-\mathrm{H}$ stretching vibrations of the hydroxyl group on the silica surface); and the peak at $971.88 \mathrm{~cm}^{-1} \mathrm{came}^{-1}$ from Si-OH vibrations [22]. In Figure $2 b$, the missing $\mathrm{Si}-\mathrm{OH}$ peak at $971.88 \mathrm{~cm}^{-1}$ was replaced by an amino group. According to TGA, the residual weight of the bare silicon sphere was $94.0 \%$ at $600{ }^{\circ} \mathrm{C}$, whereas the $\mathrm{SiO}_{2}-\mathrm{Br}$ was $89.8 \%$, indicating that $10.2 \%$ of 2-bromoisobutyryl bromide was successfully grafted. As shown in Figure 2c, peaks at around $1661.2 \mathrm{~cm}^{-1}$ and $1541.3 \mathrm{~cm}^{-1}$ of $\mathrm{SiO}_{2}-\mathrm{Br}$ are ascribed to the stretching vibration of $\mathrm{C}=\mathrm{O}$ and $\mathrm{N}-\mathrm{H}$ in $\mathrm{NH}-\mathrm{O}=\mathrm{C}$ groups, corresponding to amide I and II bands, respectively. In the spectra of $\mathrm{SiO}_{2}-\mathrm{Br}$ and $\mathrm{SiO}_{2}$-g-GAEMA, new peaks at $2925.2 \mathrm{~cm}^{-1}$ and $2879.0 \mathrm{~cm}^{-1}$ of $\mathrm{C}-\mathrm{H}$ in $\mathrm{CH}_{2}$ and $\mathrm{CH}_{3}$ were observed because the organic chain was introduced [23]. After the reaction, the remaining $\mathrm{SiO}_{2}$-g-GAEMA weights were $87.2 \%$ (reaction time $=6 \mathrm{~h}$ ), $86.6 \%$ (reaction time $=12 \mathrm{~h}$ ), and $75.7 \%$ (reaction time $=24 \mathrm{~h}$ ) at $700{ }^{\circ} \mathrm{C}$, which shows that the grafting percentage of GAEMA was $12.8 \%, 13.4 \%$ and $24.3 \%$, respectively. The vibration peak of C-H increased with 
increasing reaction time, while the stretching vibration peak of the amide bond became obvious (see Figure S3), which may be related to the increase in grafting density of the sugar-containing polymer on the surface of the silica gel.

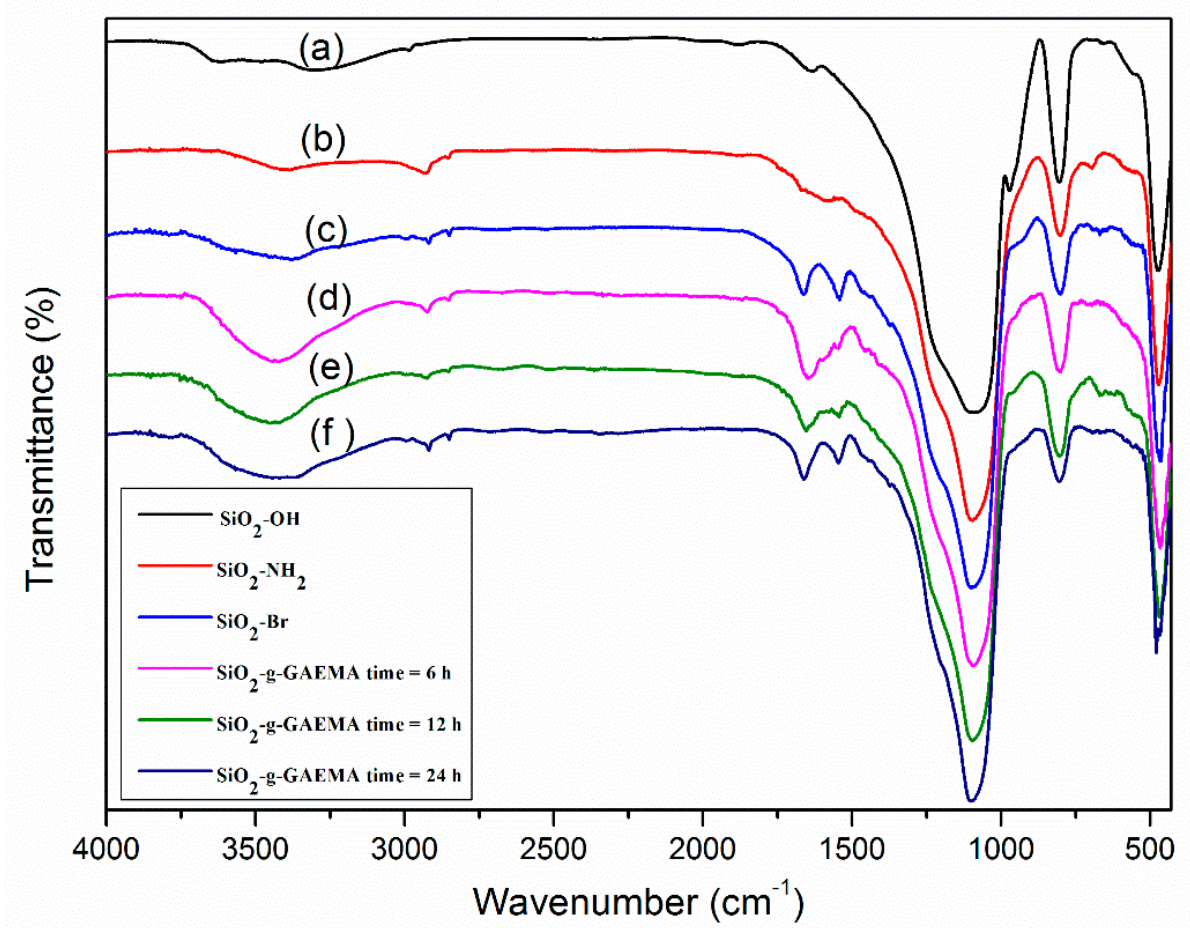

Figure 2. The FT-IR spectra of (a) bare $\mathrm{SiO}_{2}$, (b) $\mathrm{SiO}_{2}-\mathrm{NH}_{2}$, (c) $\mathrm{SiO}_{2}-\mathrm{Br}$, (d) $\mathrm{SiO}_{2}$-g-GAEMA (reaction time $=6 \mathrm{~h}$ ), (e) $\mathrm{SiO}_{2}$-g-GAEMA (reaction time $=12 \mathrm{~h}$ ), and (f) $\mathrm{SiO}_{2}$-g-GAEMA (reaction time $=24 \mathrm{~h}$ ).

\subsection{TGA Analysis}

Results from TGA analysis of the synthesized nanocomposites are shown in Figure 3. All samples showed significant weight loss at $50-180^{\circ} \mathrm{C}$, due to evaporation of the bound water on the surface. However, the bare $\mathrm{SiO}_{2}$ spheres lost more weight than the modified $\mathrm{SiO}_{2}$, possibly accounted for by surface agglomeration of the bare $\mathrm{SiO}_{2}$ sphere particles and more hydrogen bonding, resulting in the adsorption of more water molecules [23]. Another weight loss phase of the bare silicon balls occurred at $450-560{ }^{\circ} \mathrm{C}$, which may be due to the dehydroxylation of the $\mathrm{Si}-\mathrm{OH}$ surface. Figure $3 \mathrm{~b}$ shows the weight loss curve of $\mathrm{SiO}_{2}-\mathrm{Br}$. Although the initiator $\mathrm{SiO}_{2}-\mathrm{Br}$ has a wide range of weight loss, it is particularly pronounced at $210-280^{\circ} \mathrm{C}$ [24] because of the polarity and thermodynamic instability of the C-Br bond on its surface (it may release $\mathrm{Br}_{2}$ or $\mathrm{HBr}$ ) [25]. For $\mathrm{SiO}_{2}$-g-GAEMA, the $\mathrm{C}-\mathrm{Br}$ bond decomposed with the onset at $200{ }^{\circ} \mathrm{C}$, and the GAEMA decomposed with the onset at $340{ }^{\circ} \mathrm{C}$. The polymers grafted onto the silica surface can be approximately estimated to be $9 \%$ (reaction time $=6 \mathrm{~h}$ ), $11 \%$ (reaction time $=12 \mathrm{~h}$ ), and $21 \%$ (reaction time $=24 \mathrm{~h}$ ), respectively. Weight loss increased with reaction time, verifying that the GAEMA was grafted onto the silica surface in a controllable manner. 


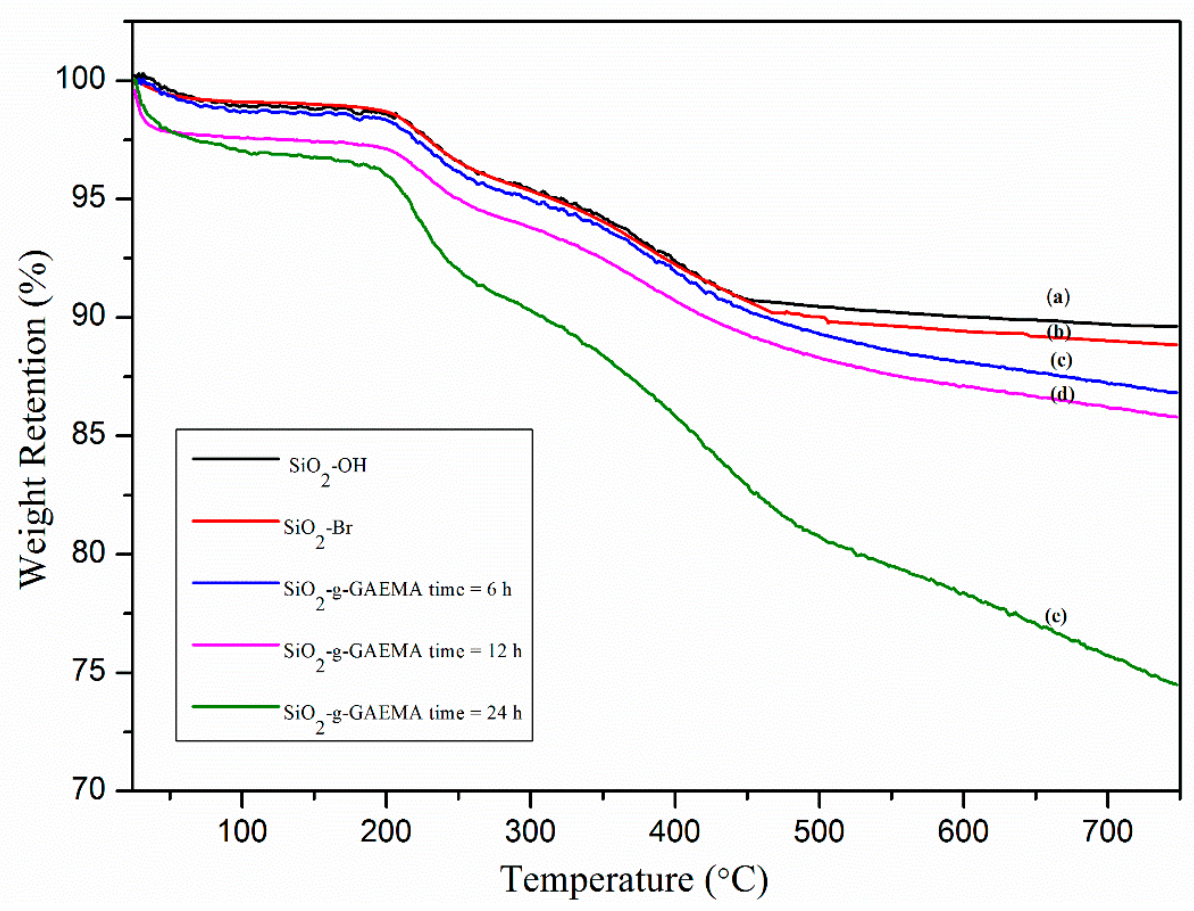

Figure 3. Thermogravimetric analysis (TGA) curves of (a) bare $\mathrm{SiO}_{2}$, (b) $\mathrm{SiO}_{2}-\mathrm{Br}$, (c) $\mathrm{SiO}_{2}-$ g-GAEMA (reaction time $=6 \mathrm{~h}$ ), (d) $\mathrm{SiO}_{2}$-g-GAEMA (reaction time $=12 \mathrm{~h}$ ), and (e) $\mathrm{SiO}_{2}$-g-GAEMA (reaction time $=24 \mathrm{~h})$.

\subsection{Characterization of GAEMA Grafted Silica Particles}

Table 1 shows that the ratio of $\mathrm{C}, \mathrm{N}$, and $\mathrm{H}$ in the brominated silica gel significantly increased compared with the bare silicon sphere, further demonstrating the synthesis of the macro-initiator $\mathrm{SiO}_{2}-\mathrm{Br}$. Table 2 shows that the grafting amount gradually increased with the extension of the reaction time, and the grafting amount was largest at $24 \mathrm{~h}$. The grafting amount did not increase further, even when the reaction time was prolonged past $24 \mathrm{~h}$. It is possible that this occurred because the concentration of the radical was kept constant during the polymerization. The radical-induced bimolecular termination and the irreversible chain-transfer reaction were limited, showing the characteristics of living polymerization [26].

Table 1. Elemental analysis of the $\mathrm{Si}-\mathrm{OH}, \mathrm{Si}-\mathrm{NH}_{2}, \mathrm{Si}-\mathrm{Br}$, and Si-g-GAEMA.

\begin{tabular}{cccc}
\hline Sample & \multicolumn{3}{c}{ Content of element } \\
\hline & $\mathbf{N}$ & $\mathbf{C}$ & $\mathbf{H}$ \\
$\mathrm{Si}-\mathrm{OH}$ & 0.030 & 1.003 & 0.300 \\
$\mathrm{Si}-\mathrm{NH}_{2}$ & 2.750 & 4.906 & 0.994 \\
$\mathrm{Si}-\mathrm{Br}$ & 1.775 & 5.070 & 0.910 \\
Si-g-GAEMA (reaction time $=6 \mathrm{~h}$ ) & 0.937 & 5.250 & 0.302 \\
Si-g-GAEMA (reaction time $=12 \mathrm{~h}$ ) & 0.890 & 7.560 & 0.357 \\
Si-g-GAEMA (reaction time $=24 \mathrm{~h}$ ) & 2.413 & 11.523 & 0.553 \\
\hline
\end{tabular}

Table 2. Characterization of GAEMA grafted silica particles with reaction times from 6 to $24 \mathrm{~h}$.

\begin{tabular}{ccc}
\hline Sample & Reaction time $(\mathrm{h})$ & Grafted $\left(\mathbf{m g} / \mathbf{m}^{2}\right)$ \\
\hline 1 & 6 & 0.50 \\
2 & 12 & 0.78 \\
3 & 24 & 1.36 \\
\hline
\end{tabular}


By linking FT-IR analysis, TGA analysis, and elemental analysis, we validated a process in which the surface of the silica gel was grafted with the sugar-containing polymer GAEMA.

\subsection{Chromatographic Performance of $\mathrm{SiO}_{2}-g-G A E M A$}

Finally, we selected a $\mathrm{SiO}_{2}$-g-GAEMA with a grafting amount of $1.36 \mathrm{mg} / \mathrm{m}^{2}$ as the chromatographic packing material, and packed the column according to the method described in Section 3.8. The chromatographic evaluation was conducted with four polar compounds (uracil, adenosine, cytosine, and cytidine). These hydrophobic probes are widely used for chromatographic evaluation [27]. Compared with bare silicon spheres, the silica gel grafted with GAEMA had a better peak shape and good efficiency in separating all compounds (as depicted in Figure 4). The chromatographic peak is considered highly symmetrical if the symmetry factor is in the range of 0.8-1.2 [28]. As shown in Table 3, the symmetry factor of the $200 \mathrm{ppm}$ uracil in the GAEMA grafted silica column (0.98) was larger than that of the unmodified silica column (0.75). The calculated $N$ values were 3960 and $8258 \mathrm{plates} / \mathrm{m}$ for the unmodified and modified silica column, respectively. To obtain sharp, narrow peaks, and good resolution, a higher $\mathrm{N}$ value is commonly needed. This indicates that room for improvement persists in the hydrophilic interaction with the chromatographic stationary phase.

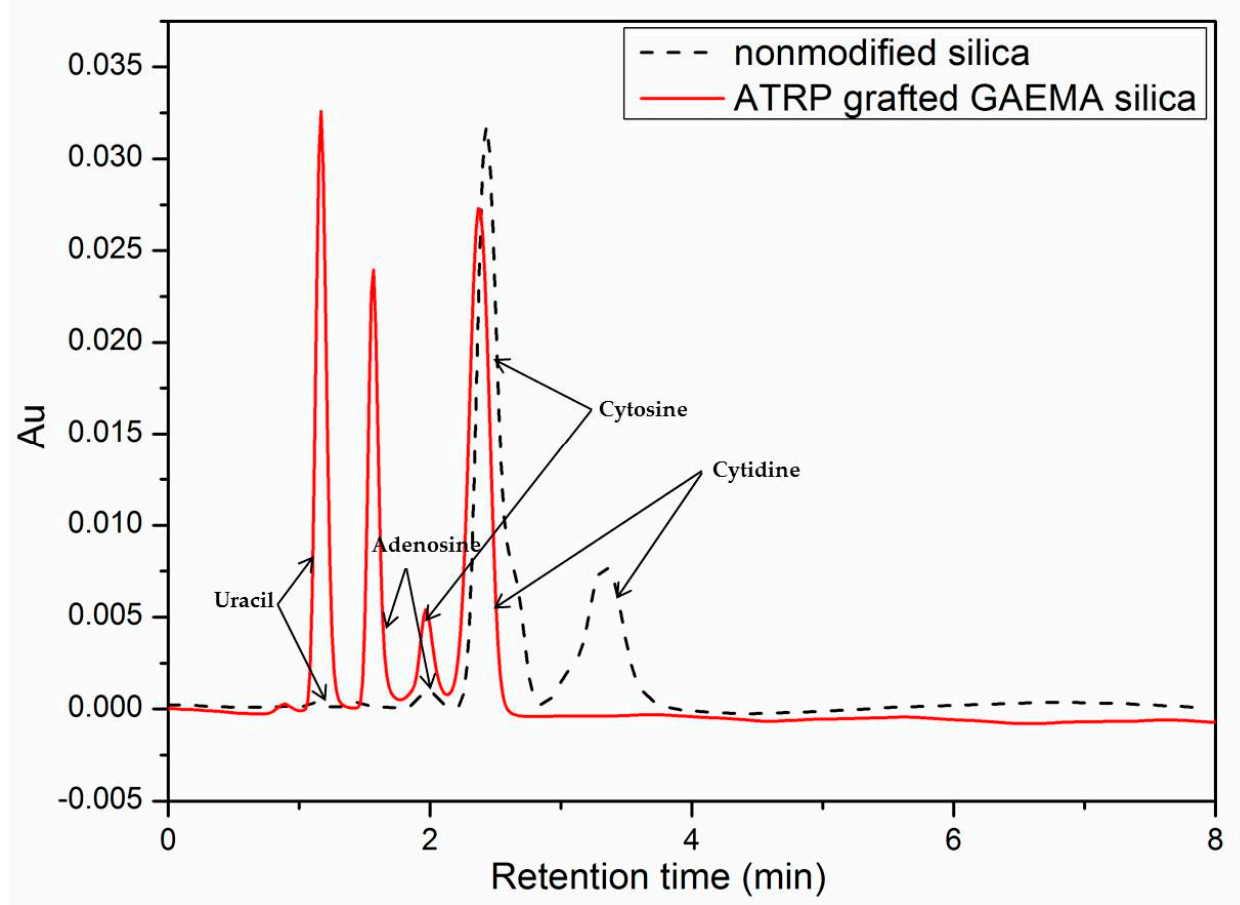

Figure 4. Hydrophilic interaction liquid chromatography (HILC) mode separation of uracil (200 ppm), adenosine (100 ppm), cytosine (50 ppm) and cytidine (200 ppm). Mobile phase: Acetonitrile $/ \mathrm{H}_{2} \mathrm{O}$ (90:10); flow rate: $1 \mathrm{~mL} / \mathrm{min}$; column temperature: $30{ }^{\circ} \mathrm{C}$; $\mathrm{UV}$ detection $(254 \mathrm{~nm})$. Dashed line is unmodified silica. Solid line indicates GAEMA grafted silica.

Table 3. Column efficiency of $\mathrm{SiO}_{2}$-g-GAEMA

\begin{tabular}{cccc}
\hline Column & Retention time (min) & N (plates/m) & Symmetry factor \\
\hline $\mathrm{SiO}_{2}-\mathrm{OH}$ & 2.687 & 3960 & 0.75 \\
$\mathrm{SiO}_{2}$-g-GAEMA & 2.380 & 8258 & 0.98 \\
\hline
\end{tabular}

\section{Materials and Methods}

High quality porous silica ( $5 \mu \mathrm{m}, 100 \AA$ ) was used as the grafting substrate for all experiments. Both 3-Aminopropyl triethoxysilane (APTES) and N, N, N', N", N"-pentamethyl diethyenetriamine 
(PMDETA) were obtained from Aladdin (Shanghai, China). Toluene (SINOPHARM, 99+\%, China) was distilled from sodium/benzophenone and stored under argon when not used. Methacryloyl chloride (Sigma-Aldrich, St. Louis, MO, USA) was filtered through basic alumina and distilled prior to use. Trichloromethane (Sinopharm Chemical Reagent Co., 99+\%, Shanghai, China) is treated with anhydrous sodium sulfate and then distilled under reduced pressure. HPLC-grade methanol and acetone were obtained from Merck KGaA. Copper (I) bromide was purchased from SIGMA-ALDRICH and purified via stirring in acetic acid, washed with ethanol, and then dried in vacuo. Triethylamine (TEA, Alfa Aesar, 99+\%, Shanghai, China) was distilled over potassium hydroxide. The 2-bromoisobutyryl bromide (Aladdin) was used as received. Ethylenediamine (MACKIN, 99+\%, China) was dried over calcium oxide and potassium hydroxide, and distilled before use following the method described by Perrin and Armarego [29]. Water was prepared in Ultra equipment (PURELAB Classic UV, Paris, France) and had a resistivity of $18.2 \mathrm{M} \Omega \mathrm{cm}^{-1}$. Cytosine was purchased from Aladdin, cytidine was purchased from Sigma (St. Louis, MO, USA), uracil was from Macklin (Shanghai, China), and adenosine was Aladdin (Shanghai, China).

\subsection{Instrumentation}

IR measurements were conducted on a Thermo Fisher Nicolet (Grand Island, NY, USA) FTIR-6700 spectrometer in $\mathrm{KBr}$ pellets at room temperature. TGA was performed on an STA-449F5 thermogravimetric analysis (Netzsch, Bavaria, Germany) using a temperature $20-750{ }^{\circ} \mathrm{C}$ of $10^{\circ} \mathrm{C} / \mathrm{min}$ in a nitrogen atmosphere flow. Elemental analyses were carried out on an GmbH Vario EL cube apparatus (Hanau, Germany). ${ }^{1} \mathrm{HNMR}$ spectra were measured with a Bruker AVANCE III $600 \mathrm{MHZ}$ spectrometer with $\mathrm{D}_{2} \mathrm{O}$ as the solvent. Chromatographic performance evaluations experiments were carried out with a Waters 1525 HPLC (Milford, MA, USA) and a Waters 2707 autosampler, a 2707 column compartment, a Waters $2489 \mathrm{UV} /$ visible detector, and a Waters 1525 binary gradient pump.

\subsection{Synthesisof 2-Aminoethyl Methacrylamide Hydrochloride (AEMA, Scheme 2 (1))}

AEMA was synthesized according to a previously reported method that was modified [30]. First, $10.1 \mathrm{~mL}$ of $15 \mathrm{mmol}$ ethylenediamine was dissolved in $150 \mathrm{~mL}$ ultrapure water at $0{ }^{\circ} \mathrm{C}$; the $\mathrm{pH}$ was adjusted to 8.5 by adding $74 \mathrm{~mL}$ of $3 \mathrm{~N} \mathrm{HCl}$ solution. Methacryloyl chloride $(16.5 \mathrm{mmol}, 16.1 \mathrm{~mL})$ diluted with anhydrous chloroform $(100 \mathrm{~mL})$, was then added to the aqueous ethylenediamine solution dropwise over $2 \mathrm{~h}$. After the addition, the reaction continued for another $2 \mathrm{~h}$ at $0{ }^{\circ} \mathrm{C}$. The aqueous and organic layers were separated, and the aqueous layer was extracted with anhydrous chloroform 3 times $(3 \times 50 \mathrm{~mL})$ to remove the unreacted methacryloyl chloride [31]. Following this, the aqueous layer was purified and concentrated under reduced pressure to obtain a white solid. The residue was washed with room temperature methanol repeatedly and filtered through a funnel. The purification is very important to successfully obtain a high purity product. Using the method of Narain et al. [32], the reaction proceeded at $-30{ }^{\circ} \mathrm{C}$, but the temperature was not easy to control and the product could not be easily purified in the recrystallization and concentration stages. On the other hand, following the method of Solomon et al. [30], the reaction proceeded at about $0{ }^{\circ} \mathrm{C}$, with a slow reaction rate and a slow yield. Herein, the reaction was held at $-5{ }^{\circ} \mathrm{C}$ and purified in liquid methanol. At the end of the concentration process, traditional filtration could be used instead of rotary steaming, which greatly reduced energy consumption and effectively increased the yield. The filtrate was finally concentrated to obtain a clear yellow oil. Finally, the solvent alone was removed under vacuum. The final product was a light-yellow powder (58\% yield). The product was characterized by ${ }^{1} \mathrm{H}$ and ${ }^{13} \mathrm{C}$ NMR. AEMA: ${ }^{1} \mathrm{H}$ NMR $\left(600 \mathrm{MHz}, \mathrm{D}_{2} \mathrm{O}\right) \delta 5.78(\mathrm{~s}, 1 \mathrm{H}), 5.51(\mathrm{~s}, 1 \mathrm{H}), 3.59(\mathrm{t}, \mathrm{J}=5.9 \mathrm{~Hz}, 2 \mathrm{H}), 3.20(\mathrm{~s}, 2 \mathrm{H})$, and $1.94(\mathrm{~s}$, 3H) (see Figure S1a).

\subsection{Synthesis of 2-Gluconamidoethyl Methacrylamide (GAEMA, Scheme 2 (2))}

A GAEMA monomer was prepared through the method reported by Narain et al. with a slight modification [20,33]. D-glucanolactone is an inexpensive and abundant raw material obtained from the 
oxidation of D-glucose. In this work, to make a solution of D-glucose lactone, it was refluxed at $60{ }^{\circ} \mathrm{C}$ for $30 \mathrm{~min}$ in methanol, which effectively reduced the reaction time and greatly decreased the amount of chromatographic pure methanol used, making the reaction highly efficient and more environmentally friendly. The specific reaction process was as follows: D-gluconolacton $(4 \mathrm{~g}, 22.45 \mathrm{mmol})$ was first dissolved in $120 \mathrm{~mL}$ methanol and refluxed at $60^{\circ} \mathrm{C}$ for $30 \mathrm{~min}$ until completely dissolved. A total of $30 \mathrm{~mL}$ AEMA ( $5 \mathrm{~g}, 30.4 \mathrm{mmol})$ methanolic solution was subsequently added. The mixed solution changed from clear to milky white and then triethylamine $(5.1 \mathrm{~mL}, 36.6 \mathrm{mmol})$ was added dropwise. The solution turned from milky white to light yellow and became transparent. The mixture was further stirred at $40{ }^{\circ} \mathrm{C}$ for $6 \mathrm{~h}$ and permitted to rest. The crude product was subsequently filtered out and washed 3 times with 2-propanol followed by acetone. The product was placed in a vacuum oven at $60^{\circ} \mathrm{C}$ for $6 \mathrm{~h}$.

The final yield after purification was $75 \%$. GAEMA was fully characterized by ${ }^{1} \mathrm{H}$ and ${ }^{13} \mathrm{C}$ NMR. GAEMA: ${ }^{1} \mathrm{H}$ NMR [GAEMA: ${ }^{1} \mathrm{H}$ NMR $\left(600 \mathrm{MHz}, \mathrm{D}_{2} \mathrm{O}\right) \delta 5.62(\mathrm{~s}, 1 \mathrm{H}), 5.38(\mathrm{~s}, 1 \mathrm{H}), 4.22(\mathrm{~d}, \mathrm{~J}=3.5 \mathrm{~Hz}$, $1 \mathrm{H}), 4.00(\mathrm{~d}, \mathrm{~J}=2.7 \mathrm{~Hz}, 1 \mathrm{H}), 3.74(\mathrm{~s}, 1 \mathrm{H}), 3.73(\mathrm{~d}, \mathrm{~J}=2.1 \mathrm{~Hz}, 1 \mathrm{H}), 3.67(\mathrm{~d}, \mathrm{~J}=5.3 \mathrm{~Hz}, 2 \mathrm{H}), 3.58(\mathrm{~d}$, $\mathrm{J}=5.8 \mathrm{~Hz}, 1 \mathrm{H}), 3.58-3.52(\mathrm{~m}, 1 \mathrm{H}), 3.43-3.36(\mathrm{~m}, 1 \mathrm{H}), 3.36(\mathrm{dd}, \mathrm{J}=11.1,6.5 \mathrm{~Hz}, 3 \mathrm{H}), 3.36-3.32(\mathrm{~m}, 2 \mathrm{H})$, $3.32(\mathrm{~d}, \mathrm{~J}=4.8 \mathrm{~Hz}, 1 \mathrm{H}), 1.84(\mathrm{~s}, 3 \mathrm{H})$ (see Figure S2a)].

\subsection{Synthesis of APTES-Modified Porous Silica with Surface Amino Group $\left(\mathrm{SiO}_{2}-\mathrm{NH}_{2}\right.$, Scheme 2 (3))}

Firstly, $5.0 \mathrm{~g}$ of $5 \mu \mathrm{m}$ silica particles were hydrolyzed in $68 \mathrm{~mL}$ of $10 \%$ hydrochloric acid at $130{ }^{\circ} \mathrm{C}$ under stirring reflux for $12 \mathrm{~h}$. The hydrolyzed silica particles were then filtered, washed with water until neutralized, and dried under vacuum at $110^{\circ} \mathrm{C}$ for $24 \mathrm{~h}$ [34]. Second, $3.0 \mathrm{~g}$ of hydrolyzed silica particles, $60 \mathrm{~mL}$ of toluene and $6 \mathrm{~mL}$ of APTES were placed in a $250 \mathrm{~mL}$ flask. After evacuating and filling with Ar three times, the flask was immersed in an oil bath at $115^{\circ} \mathrm{C}$ for $24 \mathrm{~h}$. After the end of the reflow, the resulting $\mathrm{SiO}_{2}-\mathrm{NH}_{2}$ was transferred to a sand core funnel and then purified using toluene and methanol to remove excess $\mathrm{KH}-550$. It was then dried in a vacuum oven at $60{ }^{\circ} \mathrm{C}$ until a constant weight was obtained.

\subsection{Preparation of ATRP Initiator-Immobilized Silica Particles $\left(\mathrm{SiO}_{2}-\mathrm{Br}\right.$, Scheme 2 (4))}

$\mathrm{SiO}_{2}-\mathrm{NH}_{2}(3.00 \mathrm{~g})$ dried overnight under vacuum was placed in a dried flask and dispersed in the dry toluene $(60 \mathrm{~mL})$; it reacted at room temperature for $1 \mathrm{~h}$. Next, the mixture was cooled to $0{ }^{\circ} \mathrm{C}$. To this, triethylamine $(4.5 \mathrm{~mL}, 32.1 \mathrm{mmol})$ was added dropwise over $10 \mathrm{~min}$. A solution of $1.5 \mathrm{~mL}$ of $12.45 \mathrm{mmol}$ 2-bromoisobutyryl bromide and $5 \mathrm{~mL}$ chloroform was added dropwise over $40 \mathrm{~min}$ at $0^{\circ} \mathrm{C}$. After the addition, the reaction was carried out while stirring at $0^{\circ} \mathrm{C}$ for another $2 \mathrm{~h}$. The mixture was transferred to the room temperature stirring $24 \mathrm{~h}$. The resultant alkyl bromide functionalized silica particles $\left(\mathrm{SiO}_{2}-\mathrm{Br}\right)$ were washed with ethanol five times and the excess ETOH removed by centrifugation $(10000 \mathrm{rpm}, 10 \mathrm{~min})$. The $\mathrm{SiO}_{2}-\mathrm{Br}$ silica was thereafter dried under vacuum at $50^{\circ} \mathrm{C}$ until the quality remained the same.

\subsection{Synthesis of $\mathrm{SiO}_{2}$-g-poly (2-gluconamidoethyl methacrylamide) Hybrid Microspheres via Surface-Grafted} ATRP (Scheme 2 (5))

GAEMA (1.52 g, $5.00 \mathrm{mmol})$, as the functional monomer, was heated to $60{ }^{\circ} \mathrm{C}$ to aid its dissolution in $40.0 \mathrm{~mL}$ of methanol/water $(3 / 1, v / v)$. The $\mathrm{SiO}_{2}-\mathrm{Br}$ initiator was then added, and this mixture was purged with Ar for $20 \mathrm{~min}$. CuBr (10.0 mg, $0.085 \mathrm{mmol})$ and PMDETA $(35.42 \mu \mathrm{L}$, $0.17 \mathrm{mmol}$ ) were added, and the resulting dark green solution was stirred under an Ar gas atmosphere. The polymerization mixture was deoxygenated through three freeze-pump-thaw cycles and then immersed into an oil bath preheated to $45^{\circ} \mathrm{C}$ and rotated for $24 \mathrm{~h}$. Finally, silica-grafted poly (2-gluconamidoethyl methacrylamide) $\left(\mathrm{SiO}_{2}\right.$-g-GAEMA) was collected by centrifugation ( $8000 \mathrm{rpm}$, $5 \mathrm{~min}$ ) and washed with 2-propanol, methanol, and water, successively, to remove the monomer that was not grafted. The product was dried at $60^{\circ} \mathrm{C}$ in a vacuum for $12 \mathrm{~h}$. The greenish-blue filtrate was 
washed with methanol and then freeze-dried overnight. Unreacted monomers can be used in the next synthesis to maximize monomer utilization.

\subsection{Calculation of Grafting Ratio of Sugar-Containing Polymer on Silica Gel}

The polymer grafting density was calculated from elemental analysis data as interpreted in Table 1. For the prepared graft polymer, the $\mathrm{SiO}_{2}$-g-GAEMA stationary phase was calculated using elemental analysis to obtain the graft ratio of $\mathrm{SiO}_{2}$-g-GAEMA. The graft ratio of $\mathrm{SiO}_{2}$-g-GAEMA was calculated according to the following formula [35] (1):

$$
\text { Grafted pGAEMA }=\frac{1000 \mathrm{C}}{C_{P, \text { cald. }} \times\left[1-\frac{C_{P}}{C_{P, \text { cald. }}}-\frac{C_{i}}{C_{i} \text { cald. }}\right] \times A}
$$

where $\mathrm{C}(\%)$ is the percentage of carbon in the polymer; $\mathrm{C}_{\mathrm{P}}(\%)$ is the percentage of carbon added after graft polymerization; $\mathrm{C}_{\mathrm{P} \text {, cald. }}(\%)$ is the theoretical percentage of carbon in the monomer molecule Content; $C_{i}(\%)$ is the percentage of carbon added after fixing the initiator; $C_{i, \text { cald. }}(\%)$ is the theoretical percentage of the upper carbon in the initiator unit molecule; and $\mathrm{A}$ is the specific surface area of the silica gel $\left(310 \mathrm{~m}^{2} / \mathrm{g}\right)$.

\subsection{Column Packing and Chromatographic Conditions}

$\mathrm{SiO}_{2}$-g-GAEMA was dispersed in dioxane and packed into a column (150 $\mathrm{mm} 4.6 \mathrm{~mm}$ i.d.) in a balanced density slurry packing technique using methanol as the packing solvent. The newly synthesized column was equilibrated with 90/10 acetonitrile/water for half an hour before each use, and was injected after the baseline was stable. The column was rinsed with 85/15 methanol/water for $2 \mathrm{~h}$ and the column was sealed. The efficiency and retention times were determined by HPLC using uracil (200 ppm) as a test substance in reversed phase chromatography mode. The column efficiency of this stationary phase was determined with a uracil probe, acetonitrile (ACN)/water $(90 / 10, v / v)$, at a flow rate of $1.0 \mathrm{~mL} / \mathrm{min}$, a detection wavelength of $254 \mathrm{~nm}$, and a column temperature of $30^{\circ} \mathrm{C}$.

\section{Conclusions}

A well-structured sugar-containing polymer hybrid filler was prepared through surface initiated ATRP. The initiator was immobilized on the surface of the silica particles and then used as a macroinitiator onto initiate controlled polymerization of atomic radicals on the surface. The amount of GAEMA grafted onto the surface of the silica gel substantially increased with reaction time. Next, the stability of the $\mathrm{SiO}_{2}$-g-GAEMA stationary phase was evaluated using four polar compounds (uracil, adenosine, cytosine, and cytidine), and we found that the fixed phase of the grafted sugar-containing polymer had a better peak shape and separation efficiency than the unmodified silica filler. In future research, we will separate sugar-containing systems that combine monosaccharides, disaccharides, and polysaccharides. At the same time, the effect of column temperature and $\mathrm{pH}$ of the buffer on the separation efficiency will be considered. For example, the separation of highly isomerized sugar mixtures including pentoses and hexoses is important in the sugar industry.

Supplementary Materials: Supplementary materials can be found at http:/ /www.mdpi.com/1422-0067/20/1/ 10/s1. Figure S1: (a) ${ }^{1} \mathrm{H}$ NMR spectrum $\left(\mathrm{D}_{2} \mathrm{O}\right)$ of AEMA; (b) ${ }^{13} \mathrm{C}$ NMR Spectrum $\left(\mathrm{D}_{2} \mathrm{O}\right)$ of AEMA; Figure S2: (a) ${ }^{1} \mathrm{H}$ NMR spectrum $\left(\mathrm{D}_{2} \mathrm{O}\right)$ of GAEMA; (b) ${ }^{13} \mathrm{C}$ NMR Spectrum $\left(\mathrm{D}_{2} \mathrm{O}\right)$ of GAEMA; Figure S3: shows the C-H in $\mathrm{CH}_{2}$ and $\mathrm{CH}_{3}$ of FT-IR spectra of (a) bare $\mathrm{SiO}_{2}$, (b) $\mathrm{SiO}_{2}-\mathrm{NH}_{2}$, (c) $\mathrm{SiO}_{2}-\mathrm{Br}$, (d) $\mathrm{SiO}_{2}-$ g-GAEMA time = $6 \mathrm{~h}$ ), (e) $\mathrm{SiO}_{2}$-g-GAEMA (time $=12 \mathrm{~h}$ ), and (f) $\mathrm{SiO}_{2}$-g-GAEMA (time $=24 \mathrm{~h}$ ).

Author Contributions: Q.S., W.W., X.L., and H.L. conceived and designed the experiments. G.M. performed the experiments and analyzed the data. G.M. and X.L. wrote the paper. X.S. contributed analysis tools. Q.S., W.W. and X.L. repeated to modify the manuscript. All authors have read and approved the final version of the manuscript.

Funding: This work was financially supported by the National Natural Science Foundation of China (No. 21676283), Natural Science Foundation of Shandong Province of China (ZR2018BB067), the Taishan Scholars 
Climbing Program of Shandong (No. tspd20150210), and Applied Basic Research Project of Qingdao (No. 16-5-1-31-jch).

Conflicts of Interest: The authors declare no conflict of interest.

\section{Abbreviations}

$\begin{array}{ll}\text { ATRP } & \text { Atom transfer radical polymerization } \\ \text { AEMA } & \text { 2-Aminoethyl methacrylamide hydrochloride } \\ \text { GAEMA } & \text { 2-Gluconamidoethyl Methacrylamide } \\ \mathrm{SiO}_{2} \text {-g-GAEMA } & \mathrm{SiO}_{2} \text {-g-poly (2-gluconamidoethyl methacrylamide) } \\ \text { PMDETA }^{\text {1,1,4,7,7-pentamethyldiethylenetriamine }}\end{array}$

\section{References}

1. David, A.; Kopeckova, P.J.; Rubinstein, A. The role of galactose, lactose, and galactose valency in the biorecognition of $\mathrm{N}$-(2-hydroxypropyl)methacrylamide copolymers by human colon adenocarcinoma cells. Pharm. Res. 2002, 19, 1114. [CrossRef] [PubMed]

2. Murata, J.-I.; Ohya, Y.; Ouchi, T. Possibility of application of quaternary chitosan having pendant galactose residues as gene delivery tool. Carbohydr. Polym. 1996, 29, 69-74. [CrossRef]

3. Liu, F.; Wu, Y.; Bai, L.; Peng, X.; Zhang, H.; Zhang, Y.; An, P.; Wang, S.; Ma, G.; Ba, X. Facile preparation of hyperbranched glycopolymers via an $\mathrm{AB}^{*}$ inimer promoted by a hydroxy/cerium(iv) redox process. Polym. Chem. 2018, 9, 5024-5031. [CrossRef]

4. Katagiri, K.; Takasu, A.; Higuchi, M. Synthesis of Glycopolymer Containing Cell-Penetrating Peptides as Inducers of Recombinant Protein Expression under the Control of Lactose Operator/Repressor Systems. Biomacromolecules 2016, 17, 1902-1908. [CrossRef] [PubMed]

5. Narain, R.; Armes, S.P. Synthesis of low polydispersity, controlled-structure sugar methacrylate polymers under mild conditions without protecting group chemistry. Chem. Commun. 2002, 23, 2776-2777. [CrossRef]

6. Kitano, H.; Mai, K.; Naoki Kanayama, A.; Ohno, K. Interfacial Recognition of Sugars by Novel Boronic Acid-Carrying Amphiphiles Prepared with a Lipophilic Radical Initiator. Langmuir 1998, 14, 27091-27096. [CrossRef]

7. Zhou, W.-J.; Wilson, M.E.; Kurth, M.J.; Hsieh, Y.-L.; Krochta, J.M.; Shoemaker, C.F. Synthesis and Properties of a Novel Water-Soluble Lactose-Containing Polymer and Its Cross-Linked Hydrogel. Macromolecules 1997, 30, 7063-7068. [CrossRef]

8. Kim, H.S.; Lee, B.H.; Lee, S.; Kim, H.J.; Dorgan, J.R. Enhanced interfacial adhesion, mechanical, and thermal properties of natural flour-filled biodegradable polymer bio-composites. J. Therm. Anal. Calorim. 2011, 104, 331-338. [CrossRef]

9. Yang, Q.; Xu, Z.K.; Hu, M.X.; Li, J.J.; Wu, J. Novel sequence for generating glycopolymer tethered on a membrane surface. Langmuir 2005, 21, 10717-10723. [CrossRef]

10. Morandi, G.; Heath, L.; Thielemans, W. Cellulose Nanocrystals Grafted with Polystyrene Chains through Surface-Initiated Atom Transfer Radical Polymerization (SI-ATRP). Langmuir 2009, 25, 8280-8286. [CrossRef]

11. Alpert, A.J. Hydrophilic-interaction chromatography for the separation of peptides, nucleic acids and other polar compounds. J. Chromatogr. A 1990, 499, 177-196. [CrossRef]

12. Guo, Z.; Lei, A.; Zhang, Y.; Xu, Q.; Xue, X.; Zhang, F.; Liang, X. "Click saccharides": Novel separation materials for hydrophilic interaction liquid chromatography. Chem. Commun. 2007, 28, 2491-2493. [CrossRef] [PubMed]

13. Rathnasekara, R.; El Rassi, Z. Polar silica-based stationary phases. Part II-Neutral silica stationary phases with surface bound maltose and sorbitol for hydrophilic interaction liquid chromatography. J. Chromatogr. A 2017, 1508, 24-32. [CrossRef]

14. Huang, H.; Jin, Y.; Xue, M.; Yu, L.; Fu, Q.; Ke, Y.; Chu, C.; Liang, X. A novel click chitooligosaccharide for hydrophilic interaction liquid chromatography. Chem. Commun. 2009, 45, 6973-6975. [CrossRef] [PubMed]

15. Ito, K.; Kawaguchi, S. Poly(macromonomers): Homo- and Copolymerization; Springer: Berlin/Heidelberg, Germany, 1999; Volume 142, pp. 129-178.

16. Yamada, K.; Miyazaki, M.; Ohno, K.; Fukuda, T.; Minoda, M. Atom Transfer Radical Polymerization of Poly(vinyl ether) Macromonomers. Macromolecules 1999, 32, 290-293. [CrossRef] 
17. Cheng, G.; Böker, A.; Zhang, M.; Krausch, G.; Muller, A.H.E. Amphiphilic Cylindrical Core-Shell Brushes via a "Grafting From" Process Using ATRP. Macromolecules 2001, 34, 6883-6888. [CrossRef]

18. Matyjaszewski, K.; Gaynor, S.; Wang, J.S. Controlled Radical Polymerizations: The Use of Alkyl Iodides in Degenerative Transfer. Macromolecules 1995, 28, 2093-2095. [CrossRef]

19. Gonzato, C.; Semsarilar, M.; Jones, E.R.; Li, F.; Krooshof, G.J.; Wyman, P.; Mykhaylyk, O.O.; Tuinier, R.; Armes, S.P. Rational synthesis of low-polydispersity block copolymer vesicles in concentrated solution via polymerization-induced self-assembly. J. Am. Chem. Soc. 2014, 136, 11100-11106. [CrossRef]

20. And, R.N.; Armes, S.P. Direct Synthesis and Aqueous Solution Properties of Well-Defined Cyclic Sugar Methacrylate Polymers. Macromolecules 2003, 36, 4675-4678.

21. Singleton, D.A.; Nowlan, D.T.; Jahed, N.; Matyjaszewski, K. Isotope Effects and the Mechanism of Atom Transfer Radical Polymerization. Macromolecules 2003, 36, 8609-8616. [CrossRef]

22. Macquarrie, D.J. Direct preparation of organically modified MCM-type materials. Preparation and characterisation of aminopropyl?MCM and 2-cyanoethyl?MCM. Chem. Commun. 1996, 16, 1961-1962. [CrossRef]

23. Yu, L.; Zhang, Y.; Wang, Y.; Zhang, H.; Liu, J. High flux, positively charged loose nanofiltration membrane by blending with poly (ionic liquid) brushes grafted silica spheres. J. Hazard. Mater. 2015, 287, 373-383. [CrossRef] [PubMed]

24. Wang, W.; Tang, J.; Jia, Z.; Li, X.; Xiao, Z. Grafting of amphiphilic polymers containing quaternary ammonium group on $\mathrm{SiO}_{2}$ surface via surface-initiated ATRP. J. Polym. Res. 2012, 19, 9804. [CrossRef]

25. Huang, H.; Chuang, W.; Sharma, R.C.; Hsu, C.; Lin, K.; Hu, C. Molecular elimination of Br2 in 248 nm photolysis of bromoform probed by using cavity ring-down absorption spectroscopy. J. Chem. Phys. 2004, 121, 5253-5260. [CrossRef] [PubMed]

26. Kim, J.B.; Huang, W.; Miller, M.D.; Baker, G.L.; Bruening, M.L. Kinetics of surface-initiated atom transfer radical polymerization. J. Polym. Sci. Part A Polym. Chem. 2003, 41, 386-394. [CrossRef]

27. Kimata, K.; Iwaguchi, K.; Onishi, S.; Jinno, K.; Eksteen, R.; Hosoya, K.; Araki, M.; Tanaka, N. Chromatographic Characterization of Silica C18 Packing Materials. Correlation between a Preparation Method and Retention Behavior of Stationary Phase. J. Chromatogr. Sci. 1989, 27, 721-728. [CrossRef]

28. Klejdus, B.; Petrlová, J.; Potěšil, D.; Adam, V.; Mikelová, R.; Vacek, J.; Kizek, R.; Kubáň, V. Simultaneous determination of water- and fat-soluble vitamins in pharmaceutical preparations by high-performance liquid chromatography coupled with diode array detection. Anal. Chim. Acta 2004, 520, 57-67. [CrossRef]

29. Perrin, D.D.; Armarego, W.L.F. Purification of Laboratory Chemicals; Pergamon Press: Oxford, UK, 1988; p. iv.

30. Chan, G.Y.N.; Jhingran, A.G.; Kambouris, P.A.; Looney, M.G.; Solomon, D.H. Approaches to the controlled formation of network polymers: 1 . Synthesis and evaluation of monomers with vinyl differentiation. Polymer 1998, 39, 5781-5787. [CrossRef]

31. Liu, Q.; Li, W.; Wang, H.; Newby, B.M.; Cheng, F.; Liu, L. Amino Acid-Based Zwitterionic Polymer Surfaces Highly Resist Long-Term Bacterial Adhesion. Langmuir 2016, 32, 7866-7874. [CrossRef]

32. Deng, Z.; Bouchékif, H.; Babooram, K.; Housni, A.; Choytun, N.; Narain, R. Facile synthesis of controlled-structure primary amine-based methacrylamide polymers via the reversible addition-fragmentation chain transfer process. J. Polym. Sci. Part A Polym. Chem. 2008, 46, 4984-4996. [CrossRef]

33. Lowe, A.B.; Billingham, N.C.; Armes, S.P. Synthesis and Properties of Low-Polydispersity Poly(sulfopropylbetaine)s and Their Block Copolymers. Macromolecules 1999, 32, 2141-2148. [CrossRef]

34. Niu, Y.; Ma, M.; Gong, Y.; Wang, Y.; Gong, B. Synthesis of chlorogenic acid imprinted chromatographic packing by surface-initiated atom transfer radical polymerization and its application. Chem. Res. Chin. Univ. 2014, 30, 855-862. [CrossRef]

35. Roohi, F.; Magdalena Titirici, M. Thin thermo-responsive polymer films onto the pore system of chromatographic beads via reversible addition-fragmentation chain transfer polymerization. New J. Chem. 2008, 32, 1409. [CrossRef]

(C) 2018 by the authors. Licensee MDPI, Basel, Switzerland. This article is an open access article distributed under the terms and conditions of the Creative Commons Attribution (CC BY) license (http:/ / creativecommons.org/licenses/by/4.0/). 